\title{
Improving the Drive-by Bridge Inspection Performance by Vehicle Parameter Optimization
}

\author{
Yifu Lan* \\ School of Civil and Environmental Engineering, University of New South Wales, Sydney NSW \\ 2052, Australia
}

\begin{abstract}
Keywords: Drive-by Bridge Inspection, Vehicle Bridge Interaction, Vertical Vehicle Displacement, Vehicle Configuration, Parameter Optimization
\end{abstract}

\begin{abstract}
Recently, there has been an increasing emphasis in the Indirect bridge health monitoring method employing passing vehicles, which is regarded as one of the most effective approaches in bridge damage screening. However, few researches have been conducted on the Drive-by bridge inspection method using vehicle displacement profile as damage indicator due to the challenges in displacement measurement and result accuracy. This paper proposes an optimization approach of designing the optimum vehicle parameters to improve the performance of vehicle displacement-based Drive-by bridge damage inspection. A generalized Vehicle-Bridge Interaction (VBI) system is built in MATLAB, where the bridge is modelled as a simply supported beam with 10 elements and the passing vehicle is represented as a simplified quarter car. Employing the Monte Carlo methods, the optimum parameters are determined by numerous simulations processed under diverse damage scenarios. Results show that by employing the optimal vehicle parameters, the bridge damages can be detected effectively and accurately for general damage scenarios based on the vehicle displacement profile. The proposed optimization method can contribute to the wide application of vehicle displacement-based Drive-by bridge damage inspection, providing merits in simplicity and visualization.
\end{abstract}

\section{Introduction}

It is acknowledged that more than $11 \%$ of bridges are structurally deficient in the United States, and in Europe most bridges were constructed from 1945 to 1965 (Malekjafarian et al. 2015). Issues faced by bridges these days involve not just increases in traffic loads but also the gradual deterioration due to the environmental impacts over time. The conventional SHM is known as the "sensor-base monitoring", which requires numerous sensors placed on the bridge, and its performance is highly dependent on the location and sensitivity of sensors (Sohn et al. 2003). For many years, the sensor installation has been regarded as a costly and challenging part of conventional SHM, especially for a bridge under ongoing traffic. In addition to the sensor performance, influences of the environment and ongoing traffic are non-negligible, as sensitive sensors will also be sensitive to environmental noises (Sohn et al. 2003).

To achieve a better performance in feasibility and cost efficiency, an Indirect-SHM method of employing the passing vehicle is proposed by Yang et al. (2004), regarded as one of the most effective approaches in bridge damage detection. Compared with the conventional SHM methods, advantages of the Drive-by inspection method are generally in economy, simplicity, mobility and feasibility (Malekjafarian et al. 2015). Instead of employing numerous instrumentations attached to the bridge, the Drive-by method uses a vehicle as the "moving sensor" to obtain dynamic properties of the bridge via the Vehicle-Bridge Interaction (VBI). The

\footnotetext{
* Corresponding author at: School of Civil and Environmental Engineering, University of New South Wales, Sydney NSW 2052, Australia

E-mail address: elvislannnnnn@gmail.com (Y. Lan)
} 
vehicle employed is regarded as both exciter and receiver with the instrumentation placed on the cart suspension system, which aims at eliminating the noise from the vehicle engine (Lin and Yang 2005). It has been experimental verified that the fundamental frequency of bridge can be successfully extracted by acceleration signals collected from the cart sensor with a travelling speed lower than $40 \mathrm{~km} / \mathrm{h}$. Structural damages will lead to changes in bridge dynamic properties, and it is feasible to extract the frequency changes due to bridge damage by tracking the vehicle responses.

Based on diverse damage indicators, there are generally three approaches of bridge damage inspection employing passing vehicles. The first is based on the bridge damping ratio, in which the structural damage is represented as the increase in bridge damping ratio. It is found that the damping ratio increases will lead to changes in the acceleration spectra, and by tracking these changes the damages can be detected and localized (McGetrick et al. 2009). The second is known as the mode shape-based damage inspection method, regarding the mode shape discontinuities as damage representor. Zhang et al. (2012) find that the point impedance can be obtained using the vehicle response when a specialized theoretical vehicle is employed to control the applied force on the bridge, and the amplitude of the point impedance spectra is proportional to the square of the mode shapes. Moreover, an algorithm introduced by Yang et al. (2014) shows that the instantaneous amplitude for the extracted bridge component response of specific mode is equal to the mode shape, which provides high-resolution results. In addition to the approaches introduced above, there is a trend of using displacement profile to detect the structural damages. Traditionally, the bridge deflection shape is always considered as damage representor, where the peak occurred in the displacement profile difference between healthy and damaged bridges could indicate the existence of damage.

However, there are few studies focusing on the vehicle displacement-based methods of damage inspection. Traditionally the measurement of relative vertical vehicle displacement is challenging employing the conventional measuring approaches, especially when the damage is less significant (Yin and Tang 2011). Additionally, the vehicle dynamics could mask the damage characteristics even the highly sensitive sensors are available. The relative displacement maximization and the noise reduction therefore play a key role in the damage detection using vehicle displacement profile as indicator. One of the strategies is to optimize the vehicle configuration parameters. McGetrick and Kim (2013) point out that the vehicle response will be considerably affected by its configuration parameters involving vehicle stiffness, mass and damping. Accordingly, by investigating the parametric impacts and optimizing the vehicle parameters before the bridge health monitoring can contribute to better detection performance.

This paper proposes a new method of Drive-by inspection with parameter optimization, which employs the vehicle displacement profile as damage indicator. The parameter optimization will be firstly processed to determine the vehicle parameters that provide the preferable performance. Secondly, the effectiveness of Drive-by inspection based on vehicle displacement profile difference will be examined in the presence of diverse damage positions and levels.

\section{VBI Modelling}

The bridge is established in MATLAB as a simply supported beam with 10 elements while the vehicle is modelled as a quarter car consisting of the main vehicle parameters of $m_{v}$ (vehicle mass), $k_{v}$ (vehicle stiffness), $c_{v}$ (vehicle damping) and $v$ (vehicle speed). Each element of the bridge has the equal physical properties such as rectangular cross section and density as shown in the Table. 1. The damage in this study is identified as the loss of stiffness caused by structural 
defects like cracks. The damage severity is defined as $\mathrm{x} \%$ reduction in the element, while the damage location is described as the specific element in which the damage occurs.

Table. 1 Bridge Properties

\begin{tabular}{|ccccc|}
\hline $\begin{array}{c}\text { Span } \\
\text { Length, L } \\
(\mathrm{mm})\end{array}$ & $\begin{array}{c}\text { Intact Element } \\
\text { Stiffness, EI } \\
\left(\mathrm{N}^{*} \mathrm{~m}^{2}\right)\end{array}$ & $\begin{array}{c}\text { Natural } \\
\text { Frequency, Wb } \\
(\mathrm{Rad} / \mathrm{s})\end{array}$ & $\begin{array}{c}\text { Mass per unit } \\
\text { length, } \rho(\mathrm{kg} / \mathrm{m})\end{array}$ & $\begin{array}{c}\text { Road } \\
\text { profile } \\
\text { severity }\end{array}$ \\
\hline 25000 & $3.30 \mathrm{E}+09$ & 2 & 4800 & Class A \\
\hline
\end{tabular}

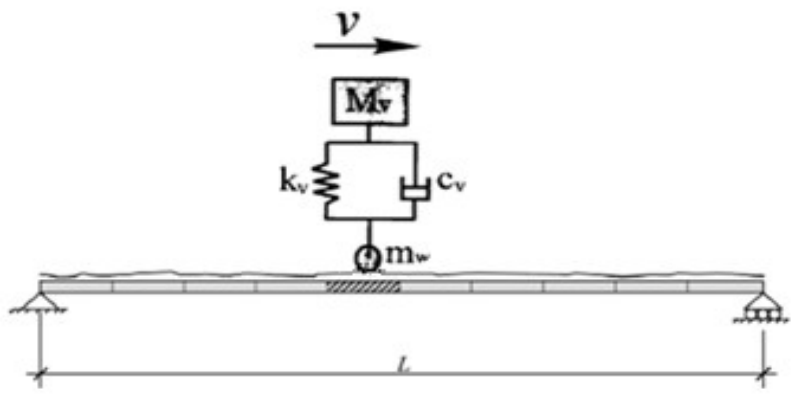

Fig. 1 VBI Model

The VBI process is simulated in MATLAB and the vehicle response can be obtained applying the contact force concept. The equations of motion of the VBI system can be given by equating the contact forces between vehicle and bridge at each moment, and for the time step $\mathrm{i}$ are:

$$
\begin{aligned}
& {\left[\mathrm{m}_{\mathrm{v}}\right]\left\{\ddot{y}_{\mathrm{v}}\right\}_{\mathrm{i}}+\left[\mathrm{c}_{\mathrm{v}}\right]\left\{\dot{y}_{\mathrm{v}}\right\}_{\mathrm{i}}+\left[\mathrm{k}_{\mathrm{v}}\right]\left\{\mathrm{y}_{\mathrm{v}}\right\}_{\mathrm{i}}=\left\{\mathrm{f}_{\mathrm{v}}\right\}_{\mathrm{i}}} \\
& {\left[\mathrm{m}_{\mathrm{b}}\right]\left\{\ddot{y}_{\mathrm{b}}\right\}_{\mathrm{i}}+\left[\mathrm{c}_{\mathrm{b}}\right]\left\{\dot{y}_{\mathrm{b}}\right\}_{\mathrm{i}}+\left[\mathrm{k}_{\mathrm{b}}\right]\left\{\mathrm{y}_{\mathrm{b}}\right\}_{\mathrm{i}}=\left\{\mathrm{f}_{\mathrm{b}}\right\}_{\mathrm{i}}}
\end{aligned}
$$

Where the $\left[\mathrm{m}_{\mathrm{v}}\right],\left[\mathrm{c}_{\mathrm{v}}\right]$ and $\left[\mathrm{k}_{\mathrm{v}}\right]$ represent mass, damping and stiffness matrices of the vehicle respectively. While $\left\{\ddot{y}_{\mathrm{v}}\right\},\left\{\dot{y}_{\mathrm{v}}\right\}$ and $\left\{\mathrm{y}_{\mathrm{v}}\right\}$ are the acceleration, velocity and displacement of vehicle respectively. Similarly, the $\left[\mathrm{m}_{\mathrm{b}}\right],\left[\mathrm{c}_{\mathrm{b}}\right]$ and $\left[\mathrm{k}_{\mathrm{b}}\right]$ are mass, damping and stiffness for bridge respectively, and $\left\{\ddot{y}_{\mathrm{b}}\right\},\left\{\dot{y}_{\mathrm{b}}\right\}$ and $\left\{\mathrm{y}_{\mathrm{b}}\right\}$ are bridge acceleration, velocity and displacement respectively. Accordingly, the non-zero components of the vector, $\left\{f_{v}\right\}_{i}$ represent the dynamic interaction forces:

$$
\mathrm{f}_{\mathrm{vci}}=\left(\mathrm{wbi}_{\mathrm{b}}+\mathrm{r}_{\mathrm{i}}\right) \mathrm{k}_{\mathrm{s}}
$$

Where $\mathrm{k}_{\mathrm{s}}$ is the suspension stiffness and $\mathrm{w}_{\mathrm{bi}}$ is the deflection of bridge, while in the equation, $\mathrm{r}_{\mathrm{i}}$ represents the road profile height. and $\left\{\mathrm{f}_{\mathrm{b}}\right\}_{\mathrm{i}}$ is the applied force vector on the bridge, which is given as:

$$
\left\{\mathrm{f}_{\mathrm{b}}\right\}_{\mathrm{i}}=\left(\mathrm{w}-\left[\mathrm{m}_{\mathrm{v}}\right]\left\{\ddot{y}_{\mathrm{v}}\right\}_{\mathrm{i}}\right) *\left\{\mathrm{~N}_{\mathrm{b}}\right\}_{\mathrm{i}}
$$

Where $\mathrm{w}$ is the vehicle gravity weight and $\left\{\mathrm{N}_{\mathrm{b}}\right\}_{\mathrm{i}}$ is the location function that assigns the interaction force to the element degrees of freedom at the $i$ th step.

By solving the iterative process, the bridge displacement under the vehicle can be calculated until the increase in the bridge displacement is less than the specified percentage. Firstly, it is assumed that there is no deflection occurred on the bridge and the vehicle interactive force is calculated for the whole simulation using Eq. 3. Secondly, the vehicle response is obtained by solving the Eq. 1 using Newmark-beta integration scheme. Thirdly, the vehicle accelerations obtained are used in Eq. 4 to calculate the applied force on the bridge, after which the bridge 
deflection vector is calculated by Newmark-beta integration scheme. Lastly, the bridge displacement is computed as below:

$$
\mathrm{W}_{\mathrm{bi}}=\left\{\mathrm{yb}_{\mathrm{b}}\right\}_{\mathrm{i}}^{\mathrm{T}}\left\{\mathrm{N}_{\mathrm{b}}\right\} \mathrm{i}
$$

The vector $\left\{\mathrm{y}_{\mathrm{v}}\right\}$ is obtained by repeating the same process for all $i$ steps, which is the vehicle displacement corresponding to each time step. The process will be proceeded repeatedly using the new wbi until less than $1 \%$ is witnessed in the ratio between the max bridge displacements in the old and new profiles. Fig. 2 below illustrates the VBI algorithm.

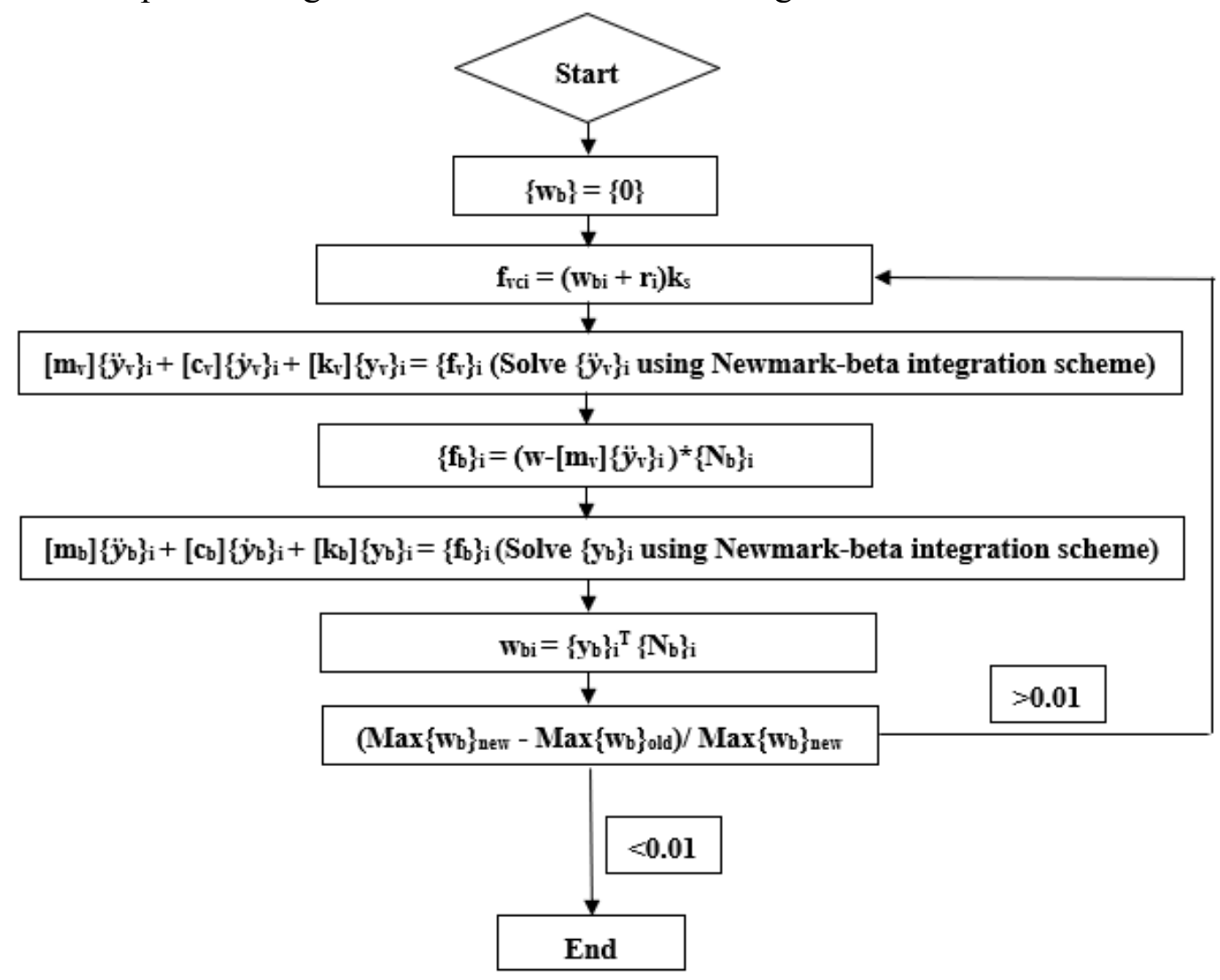

Fig. 2 Flow chart of VBI algorithm

\section{Optimization of the vehicle parameters}

The parameters being assessed involve $\mathrm{m}_{\mathrm{v}}$ (vehicle mass), $\mathrm{k}_{\mathrm{v}}$ (vehicle stiffness), $\mathrm{c}_{\mathrm{v}}$ (vehicle damping) and $\mathrm{v}$ (vehicle speed), which accordingly would have considerable impacts on vehicle responses (McGetrick and Kim 2013). A feasible strategy is by employing the Monte Carlo Method, which aims to solve deterministic problems utilizing repeated samplings, to investigate the parameter effects. Each vehicle parameter of interest in this study is independent (would not affect or be affected by other parameters) and it is reasonable to study these parameters separately.

The value of interest parameter will be changed many times within the range while other 3 vehicle parameters remaining constant to obtain the vehicle responses. The corresponding displacement difference profile of vehicle between healthy and damaged beams will be acquired as the vehicle parameter varies. After that, a diagram of the max displacement differences corresponding to the parameter changes can be generated after many times of repetition, where the optimum vehicle parameters can be designed. Initializing that $\mathrm{v}=15 \mathrm{~m} / \mathrm{s}, \mathrm{m}_{\mathrm{v}}=10000 \mathrm{~kg}$, 
$\mathrm{k}_{\mathrm{v}}=250000 \mathrm{~N} / \mathrm{m}$ and zeta $=0.05$, the changes in the max displacement differences corresponding to vehicle damping ratio (zeta), vehicle stiffness $\left(\mathrm{k}_{\mathrm{v}}\right)$, vehicle mass $\left(\mathrm{m}_{\mathrm{v}}\right)$ and speed (v) respectively for Damaged Element 2 and 5 with 20\% severity are given as shown in Fig. $3-4$.

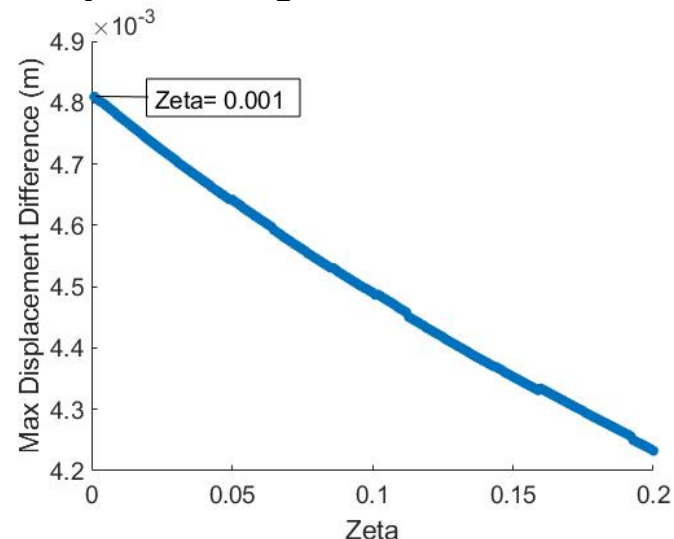

(a)

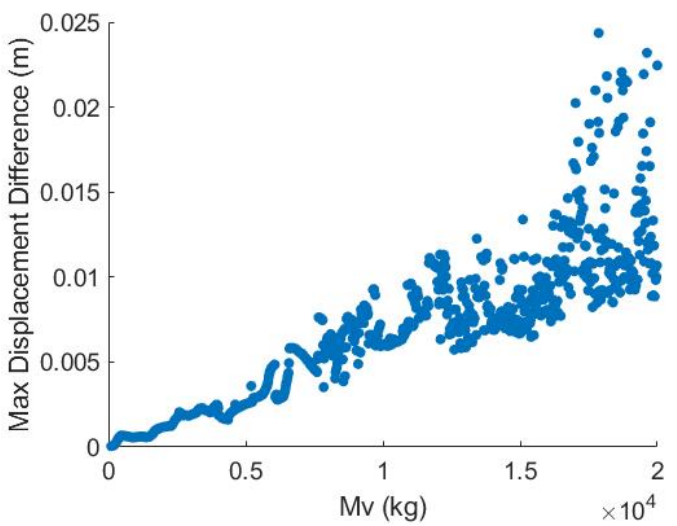

(c)

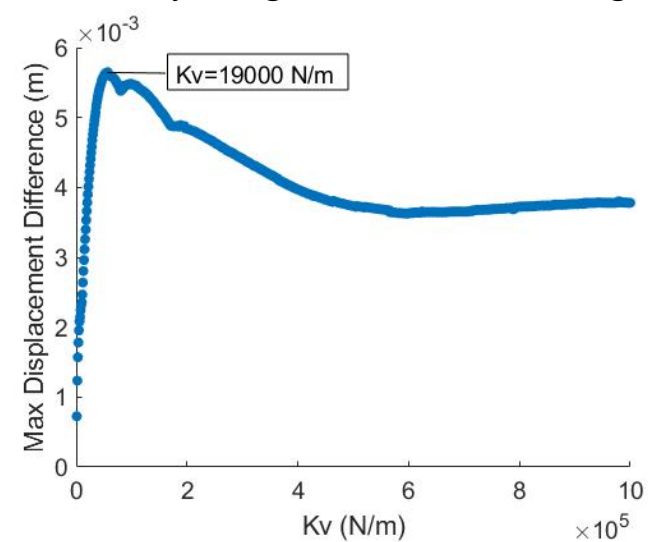

(b)

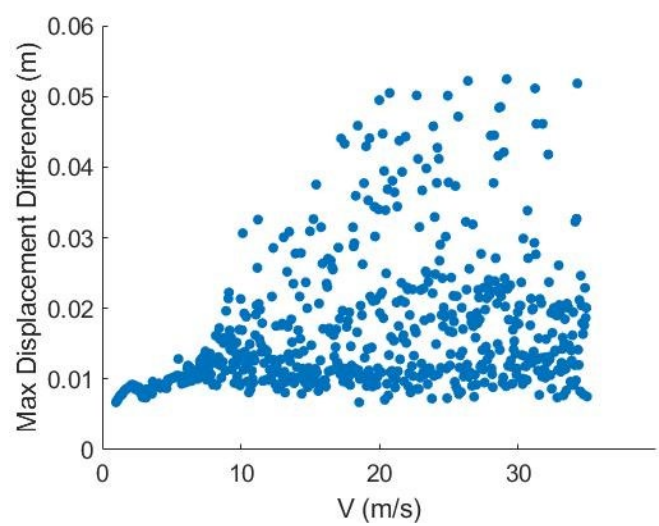

(d)

Fig. 3 The max displacement differences corresponding to diverse vehicle parameters for Damaged Element 2: (a) Vehicle damping ratio, zeta (b) Vehicle stiffness, $k_{v}(c)$ Vehicle mass, $m_{v}$ (d) Vehicle speed, $v$

Summarily, the max displacement difference rises with vehicle mass ignoring some fluctuations and declines as vehicle damping ratio increases. As shown in the relation between $\mathrm{k}_{\mathrm{V}}$ and the max displacement difference, it rises sharply to the peak and then drops dramatically to a lower point. As the $\mathrm{k}_{\mathrm{v}}$ continues to increase, it presents a stable trend of the connection between vehicle stiffness and the max displacement difference. The correlations between vehicle speed and the max displacement difference are blurry when the speed reaches high. As the cart might be "over-excited" with the high travel speed, and this would mask the responses corresponding to bridge damages. Additionally, higher resolution results can be provided by the lower speed of vehicle. Results for damage locations in Element $6 \& 8$ present similar trends, and the optimal parameters can therefore be acquired as shown in Table 2 below, which provide preferable performances for diverse Damage Situations. 


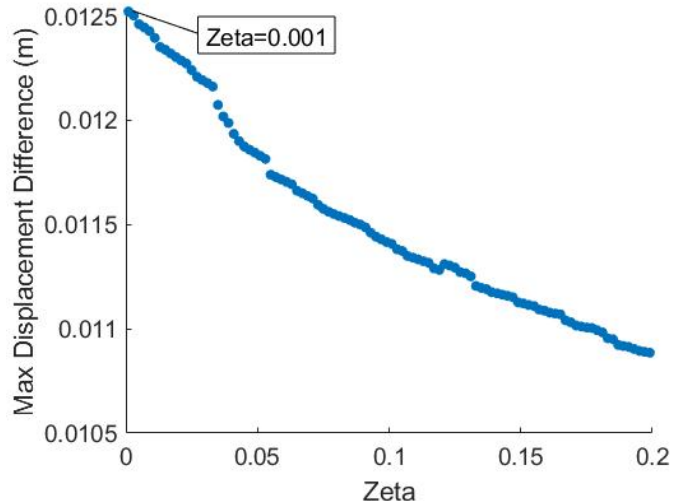

(a)

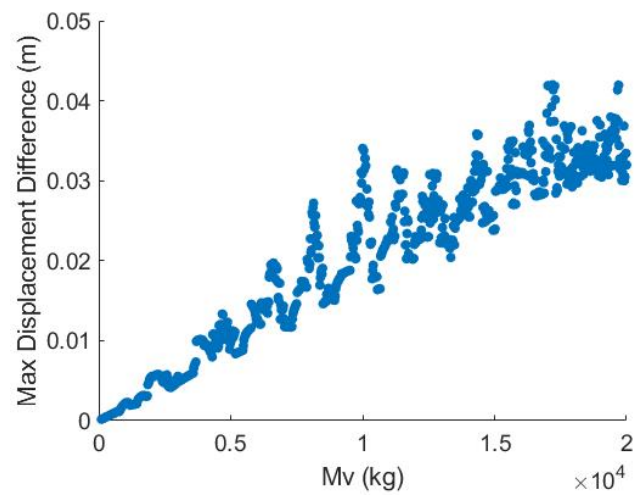

(c)

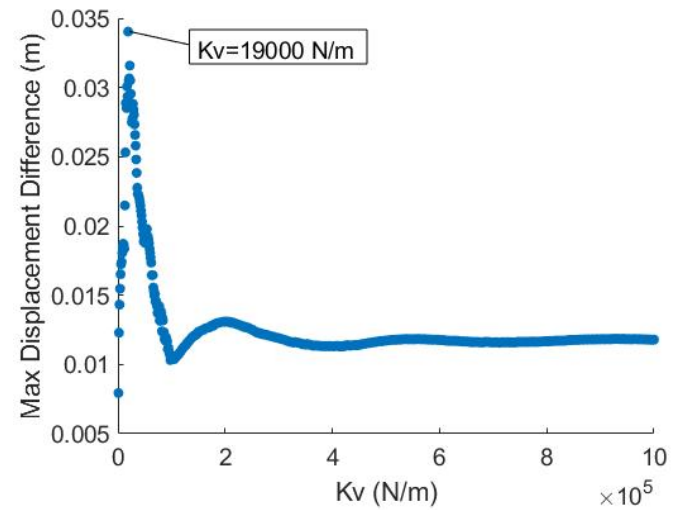

(b)

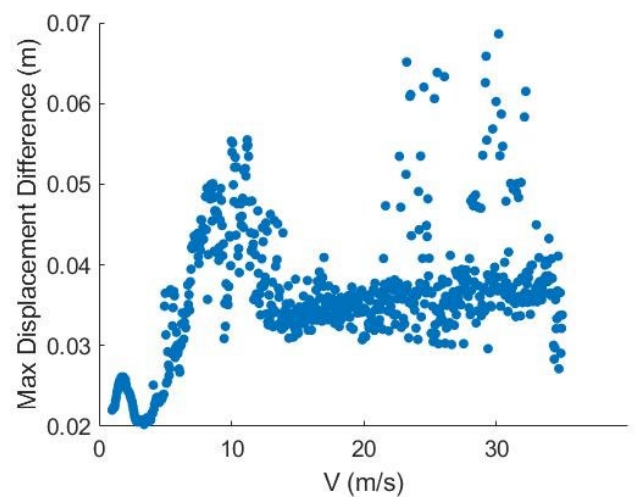

(d)

Fig. 4 The max displacement differences corresponding to diverse vehicle parameters for Damaged Element 5: (a) Vehicle damping ratio, zeta (b) Vehicle stiffness, $k_{v}(c)$ Vehicle mass, $m_{v}$ (d) Vehicle speed, $v$

Table. 2 The optimum vehicle parameters for diverse damage scenarios

\begin{tabular}{|c|c|c|c|c|} 
& $\begin{array}{c}\text { Damaged } \\
\text { Element 2 }\end{array}$ & $\begin{array}{c}\text { Damaged } \\
\text { Element 5 }\end{array}$ & $\begin{array}{c}\text { Damaged } \\
\text { Element 6 }\end{array}$ & $\begin{array}{c}\text { Damaged } \\
\text { Element 8 }\end{array}$ \\
\hline Zeta & 0.001 & 0.001 & 0.001 & 0.001 \\
\hline $\mathrm{K}_{\mathrm{v}}$ & $19000 \mathrm{~N} / \mathrm{m}$ & $19000 \mathrm{~N} / \mathrm{m}$ & $18000 \mathrm{~N} / \mathrm{m}$ & $12000 \mathrm{~N} / \mathrm{m}$ \\
\hline $\mathrm{M}_{\mathrm{v}}$ & $20000 \mathrm{~kg}$ & $20000 \mathrm{~kg}$ & $20000 \mathrm{~kg}$ & $20000 \mathrm{~kg}$ \\
\hline $\mathrm{V}$ & $1 \mathrm{~m} / \mathrm{s}$ & $1 \mathrm{~m} / \mathrm{s}$ & $1 \mathrm{~m} / \mathrm{s}$ & $1 \mathrm{~m} / \mathrm{s}$ \\
\hline
\end{tabular}

\section{Results of damage inspection using the optimum parameters}

Damages are presented in Element 2, 5, 6 \& 8 with damage level increasing from $10 \%$ to $80 \%$ gradually, defined as the loss of element stiffness. To detect the damage, the vehicle with optimum parameters obtained above is simulated travelling through the beam. The vehicle displacement difference profiles are then obtained based on the differences between vehicle time histories of damaged beams and the baseline, where the baseline is acquired using the vehicle deflection profile of healthy beam. Ideally, the peaks occurred will accurately indicate the location of damage and the damage levels will be illustrated as the increasement in displacement 
difference, which are known as the damage characteristics (Yin and Tang 2011). In damage scenario 1, where the stiffness reduction starts at element $2(20 \% \mathrm{~L})$, the peak occurs at around 5 $\mathrm{s}$ in Displacement difference profile, $20 \%$ of the total time period. When the structural damage occurs in element $5(50 \% \mathrm{~L})$, it can be found that the peak is witnessed at about $12.5 \mathrm{~s}$ in Displacement difference profile, which is nearly $50 \%$ of the total time period. Similarly, in Displacement difference profiles of damage scenario $3 \& 4$, where bridge damages are presented in element $6 \& 8$, the peaks occur just before $15 \mathrm{~s}$ and $20 \mathrm{~s}$ respectively, which are $60 \%$ and $80 \%$ of the total time period respectively. Generally, as shown in Fig. 5, the displacement difference between baseline (healthy) and that of damaged beam increases gradually as the damage level goes up. The results indicate that this approach presents high accuracy and sensitivity in damage inspection.

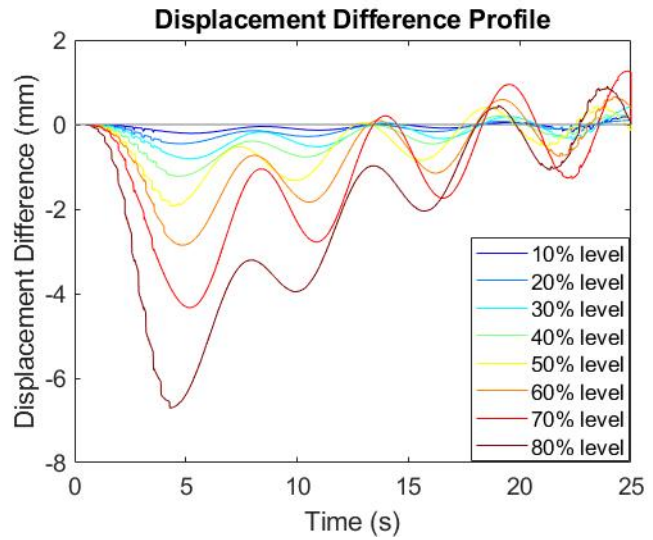

(a)

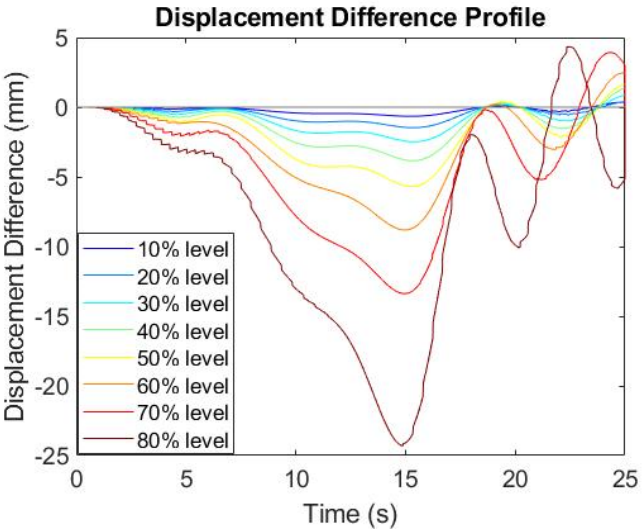

(c)
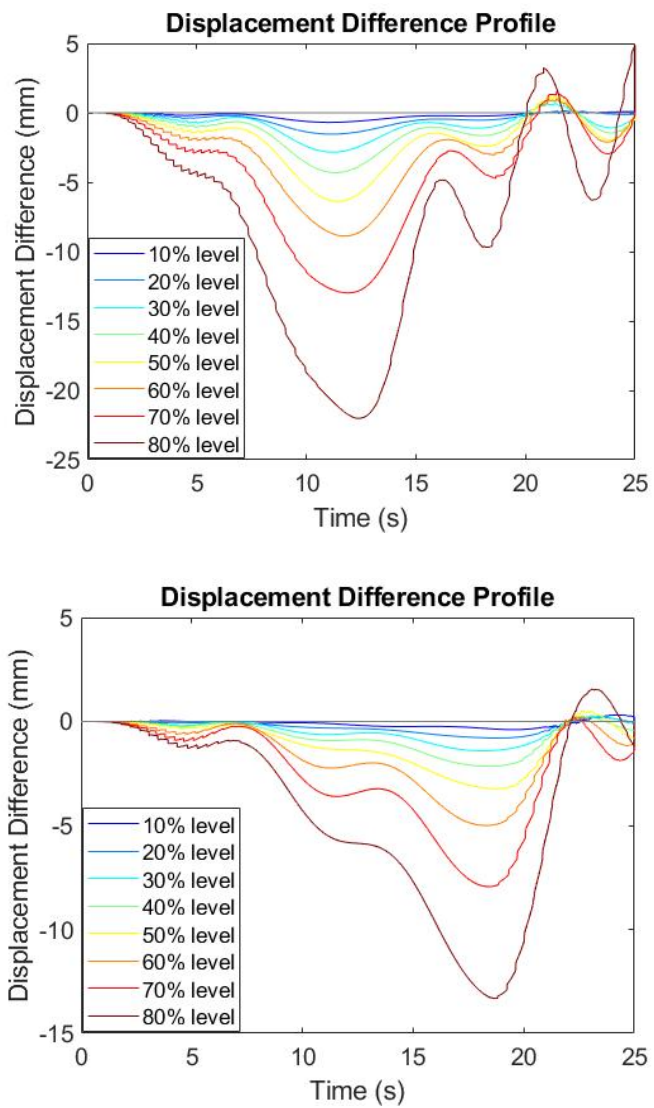

Fig. 5 Displacement Difference Profile for diverse damage locations: (a) Damaged element 2, 20\% L (b) Damaged element 5, 50\% L (c) Damaged element 6, 60\% L (d) Damaged element 8, $80 \% \mathrm{~L}$

\section{Conclusion}

This paper proposes a new method of Drive-by inspection with parameter optimization employing vehicle displacement as damage indicator. The vehicle time history is adopted employing a simplified VBI system simulated in MATLAB. Then the displacement difference profile of vehicle can be obtained by subtracting the vehicle time histories between baseline and that of damaged bridge, where the baseline is acquired by the first-time run passing through the bridge with healthy condition. In many times of simulations, it is found that the occurrence of 
damages can be successfully identified, which is presented as the peak in displacement difference profile, while the damage level is regarded as the increasement in displacement difference. To achieve higher accuracy and sensitivity of detection results, this paper proposes a strategy of parameter optimization aiming at maximizing the vehicle displacement profile difference and reducing the noises from vehicle dynamics. The results indicate that the optimum parameters of vehicle can effectively improve the inspection performance for all damage scenarios. With the technique of deflectometer developing rapidly, it is predictable that the role of Vehicle response-based Drive-by inspection will become increasingly emphasized. The effectiveness of this approach can contribute to its wide application to the general health monitoring. To further study its feasibility and applicability in real project, field tests including the environmental effects are required.

\section{References}

[1] Malekjafarian, A., McGetrick, P. \& O’Brien, E. 2015, 'A Review of Indirect Bridge Monitoring Using Passing Vehicles', Shock and Vibration, vol.2015, pp.1-16. https://doi.org/10.1155/2015/286139

[2] Sohn, H., Farrar, C.R., Hemez, F.M., Shunk, D.D., Stinemates, D.W., Nadler, B.R. \& Czarnecki, J.J. 2003, 'A review of structural health monitoring literature: 1996-2001', Los Alamos National Laboratory, USA.

[3] Yang, Y., Lin, C. \& Yau, J. 2004, 'Extracting bridge frequencies from the dynamic response of a passing vehicle', Journal of Sound and Vibration, vol. 272, no. 3-5, pp. 471-493. https://doi.org/10.1016/S0022-460X(03)00378-X

[4] Yang, Y. \& Lin, C. 2005, 'Vehicle-bridge interaction dynamics and potential applications', Journal of Sound and Vibration, vol. 284, no. 1-2, pp. 205-226.

https://doi.org/10.1016/j.jsv.2004.06.032

[5] McGetrick, P.J., Gonzlez, A. \& Obrien, E.J. 2009, 'Theoretical investigation of the use of a moving vehicle to identify bridge dynamic parameters', Insight - Non-Destructive Testing and Condition Monitoring, vol. 51, no. 8, pp. 433-438. https://doi.org/10.1784/insi.2009.51.8.433

[6] Zhang, Y., Wang, L. \& Xiang, Z. 2012, 'Damage detection by mode shape squares extracted from a passing vehicle', Journal of Sound and Vibration, vol. 331, no. 2, pp. 291-307.

https://doi.org/10.1016/j.jsv.2011.09.004

[7] Yang, Y., Li, Y. \& Chang, K. 2014, 'Constructing the mode shapes of a bridge from a passing vehicle: a theoretical study', SMART STRUCTURES AND SYSTEMS, vol. 13, no. 5, pp. 797-819. https://doi.org/10.12989/sss.2014.13.5.797

[8] McGetrick, P.J. \& Kim, C.W. 2013, 'A Parametric Study of a Drive by Bridge Inspection System Based on the Morlet Wavelet', Key Engineering Materials, pp. 569-570 \& pp. 262-269. https://doi.org/10.4028/www.scientific.net/KEM.569-570.262

[9] Yin, S.H. \& Tang, C.Y. 2011, 'Identifying Cable Tension Loss and Deck Damage in a CableStayed Bridge Using a Moving Vehicle', Journal of Vibration and Acoustics, vol. 133, no.2/ 021007. https://doi.org/10.1115/1.4002128 